\title{
PHYSIOLOGY OF THE URINARY SPHINCTER AND ITS RELATION TO OPERATIONS FOR INCONTINENCE ${ }^{1}$
}

\author{
By JACK LAPIDES, M.D. \\ From the University of Michigan Medical Center, Ann Arbor, Michigan
}

UNTIL recently the physiopathology of non-neurogenic urinary incontinence was unknown and the therapy empirical. As a result, many operations had been devised and most have had only a measure of success. It was obvious that the identification of the cause and establishment of appropriate therapy for urinary incontinence awaited the development of knowledge of the normal physiology of the bladder and urinary sphincter.

Although extensive research has been performed on micturition for many years, a clear concept did not emerge until the present. Four important milestones in the evolution of the modern concept include the discoveries that $(a)$ bladder smooth muscle possesses inherent tonicity (Nesbit and Lapides, 1948; Tang and Ruch, 1955), (b) bladder smooth muscle is under direct cortical control (Lapides et al., 1957), (c) bladder smooth muscle is activated solely through the parasympathetic nerves (Lapides, 1958), and $(d)$ the urinary sphincter is a tubular structure (Lapides, 1958; Woodburne, 1960).

Physiology of Micturition.-Urination is a simple process governed by the higher centres in the normal individual. The bladder consists not only of a globular portion called the fundus but also of a tubular part commonly known as the urethra. The muscular layer of the urethra is a continuation of the muscle in the wall of the bladder and is innervated by the same parasympathetic fibres. The smooth muscle of the bladder possesses the qualities of tonicity and accommodation which are inherent in the smooth muscle, and independent of motor impulses from the central nervous system.

The fundus or globular portion of the bladder receives urine continually from the ureters and stores it at relatively low pressures until capacity is reached. The urine is prevented from flowing out of the bladder during the period of storage by the urinary sphincter (Fig. 1). The urinary sphincter has been found to be a tubular structure synonymous with the proximal three-fourths of the female urethra or the prostatic and membranous portions of the male urethra; in both male and female these segments of urethra represent true bladder neck (Lapides, 1958; Lapides et al., 1960). The wall of the urethra contains much elastic tissue in addition to smooth muscle (Woodburne, 1960). The urinary sphincter maintains continence by virtue of the resistance its apposing walls present to fluid pressure. The elastic and muscle fibres in the urethral wall keep the lumen of the urethra narrow without the aid of motor impulses from the central nervous system. Thus the storage of urine by the bladder (fundus and neck) is a very efficient process in that it is performed in an autonomous, tireless fashion with a negligible expenditure of energy.

When intravesical pressure is markedly elevated by exertion, urethral resistance must be increased to prevent urinary incontinence. In the normal male and female human this is accomplished by the twofold action of the striated muscle of the urogenital diaphragm and pelvic floor (Lapides et al., 1960 a). These muscles compress the urethra or urinary sphincter circumferentially as well as elongate it by pulling it cephalad towards the fundus (Fig. 1). The net result of the striped muscle activity is to decrease the calibre of the urethral lumen, to increase the tension of the urethral walls against its lumen, and to increase the length of the urethra-all factors which increase the resistance of the urinary sphincter to the flow of fluid through it.

1 Read at the London Meeting of the International Federation of Surgical Colleges at Lincoln's Inn Fields, London, October 1960. 
When active urination occurs the urinary sphincter or urethra decreases its resistance markedly. This is attained primarily by contraction of the longitudinal muscle of the bladder fundus and urethra. The bladder fundus contracts down upon the bolus of urine and simultaneously pulls open the tubular bladder neck to expel the urine (Lapides, 1958; Woodburne, 1960) - an action somewhat similar to the widening of the cervical neck as the uterine fundus contracts down upon the fotus. In the process of being pulled open the urethral lumen is enlarged, the tension of the urethral wall against its lumen is lessened, and the urethral length is shortened (Fig. 1).

Physiopathology of Urinary Incontinence.--Studies in women with urinary incontinence (Lapides et al., $1960 \mathrm{~b}$ ) reveal that the basic lesion is a decrease in the functional length of the

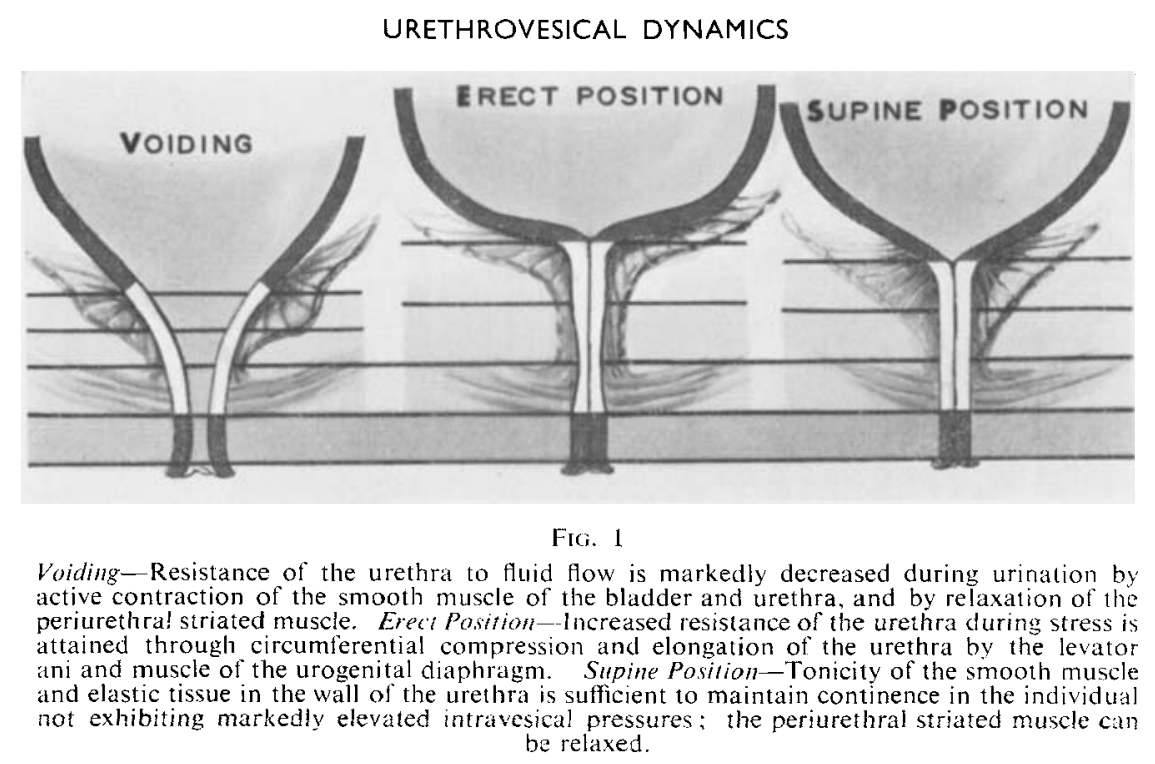

urethra. Normal young women have been found to have a urethra of approximately $3.8 \mathrm{~cm}$. in length when the pelvic striated musculature is relaxed, and an increase in length to $4.3 \mathrm{~cm}$. when exertion results in contraction of the levator ani and muscle of the urogenital diaphragm.

Most female patients with stress incontinence have a urethra of less than $3 \mathrm{~cm}$. in length in the standing position. The urethra may be normal in length in the supine position. but on assuming the erect position the urethra collapses or telescopes to a shorter length. Some patients with stress incontinence have been observed to have a normal urethral length in the erect position, but on endoscopy demonstrate a defect in some portion of the urethral wall such as an area of scar tissue or a urethrovaginal fistula. In essence, the defects shorten the functional length of the urinary sphincter. An efficient urinary sphincter is one that has tonic muscle and elastic tissue throughout a length of approximately $3 \mathrm{~cm}$. The shorter the length of intact urethra, the more severe the incontinence.

Stress incontinence evolves into a constant, dripping incontinence when the defect extends along the entire length of urethra. Lesions of this type are usually iatrogenic in origin and may follow transvaginal or transurethral operative procedures.

It is apparent that an accurate diagnosis of the type of urinary incontinence (Lapides, 1959) and its ætiology may require a battery of examinations including neurological workup, pyelography, cystometry, urethroscopy, and measurement of urethral length. 


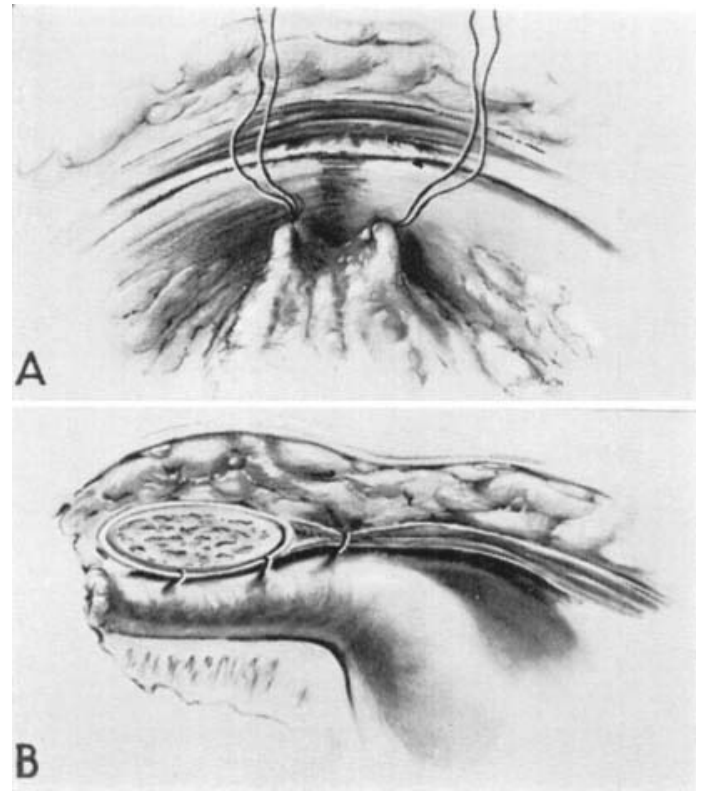

Fig. 2.- Transverse and sagittal sections through the area of urethropexy demonstrate method by which the urethra or urinary sphincter is elongated and fixed in position.

FIG. 2

Fig. 3.-First step in treating stress incontinence caused by area of scar tissue in posterior urethral wall is to raise a vaginal flap.

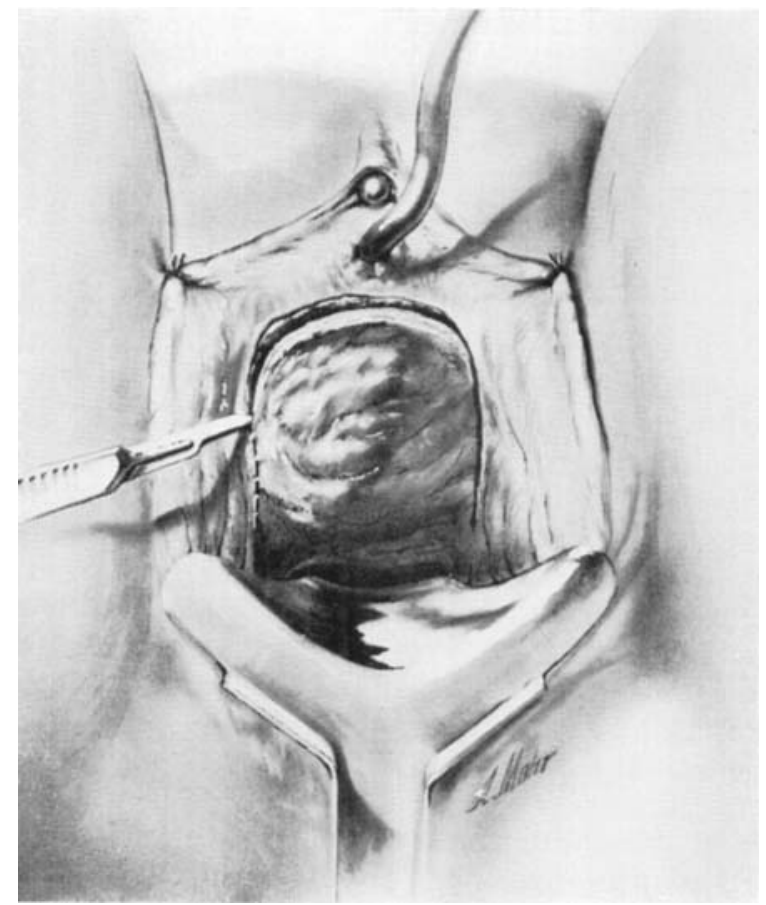

Fia. 3 
Treatment of Urinary Incontinence.-Since the basic lesion in most cases of non-neurogenic urinary incontinence is a decrease in the functional length of the urethra, then logical therapy should attempt to increase functional length. If the length of the urinary sphincter shortens significantly in the standing position (as is the case in most female patients with stress incontinence), then appropriate treatment is to stretch the urethra longitudinally and fasten it in the simplest and most certain fashion so that shortening of the urethra does not occur when the patient gets to her feet. This does not mean such unphysiological, indirect, and uncertain procedures as colporrhaphy, fascial slings, uterine suspension, vesico-urethrolysis, etc. The

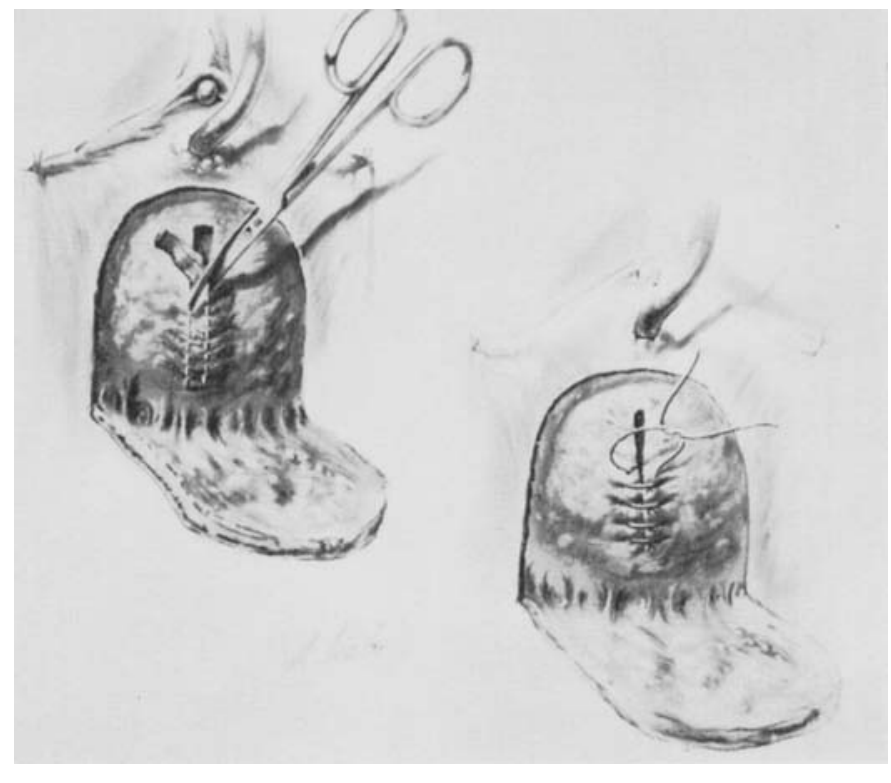

FIG. 4

The area of scar tissue is excised and the muscular layer of the urethral wall approximated.

concept that it is necessary to buttress the posterior aspect of the urethra is erroneous and should be discarded. Stress incontinence can occur without the presence of cystocele, urethrocele, or uterovaginal descensus; and when stress incontinence is associated with the presence of cystocele, simple fixation of the anterior wall or roof of the urethra to overlying symphysis pubis and rectus fascia (Fig. 2) will cure the stress incontinence without overtly changing the status of the cystocele. The lengthening and fixation of the urethra is accomplished most efficiently via a suprapubic approach (Lapides et al., 1960 b).

When stress incontinence is associated with a urethral defect such as scarring or fistula, but with a normal measured length of urethra in the erect position, then therapy should be directed towards excision of the fibrous tissue or fistula and reapproximation of the margins of normal urethral wall. By removing the atonic, inelastic area of scar tissue and replacing it with normal urethral wall, adequate functional length can be restored to the urinary sphincter. Since most of the defects are situated on the floor or posterior wall of the urethra, a transvaginal approach is used to repair the urinary sphincter. In order to provide a solid, vascular base for good healing of the urethra, the anterior vaginal wall is dissected free from its bed in the form of a flap, with its apex near the urethral meatus and its base adjacent to the cervix as illustrated in Fig. 3. The defective area in the urethra is excised and the margins of normal urethral wall are apposed in a longitudinal fashion by taking interrupted catgut sutures through the tough periurethral tissue 
(Fig. 4). If the scar tissue runs the total length of the urethra, then the entire floor of the urethra is excised and the edges reapproximated as described. The operation is concluded by replacing the anterior vaginal wall so that it covers the repaired urethra (Fig. 5).

Some patients with urinary incontinence may have not only a defect of the urethral wall

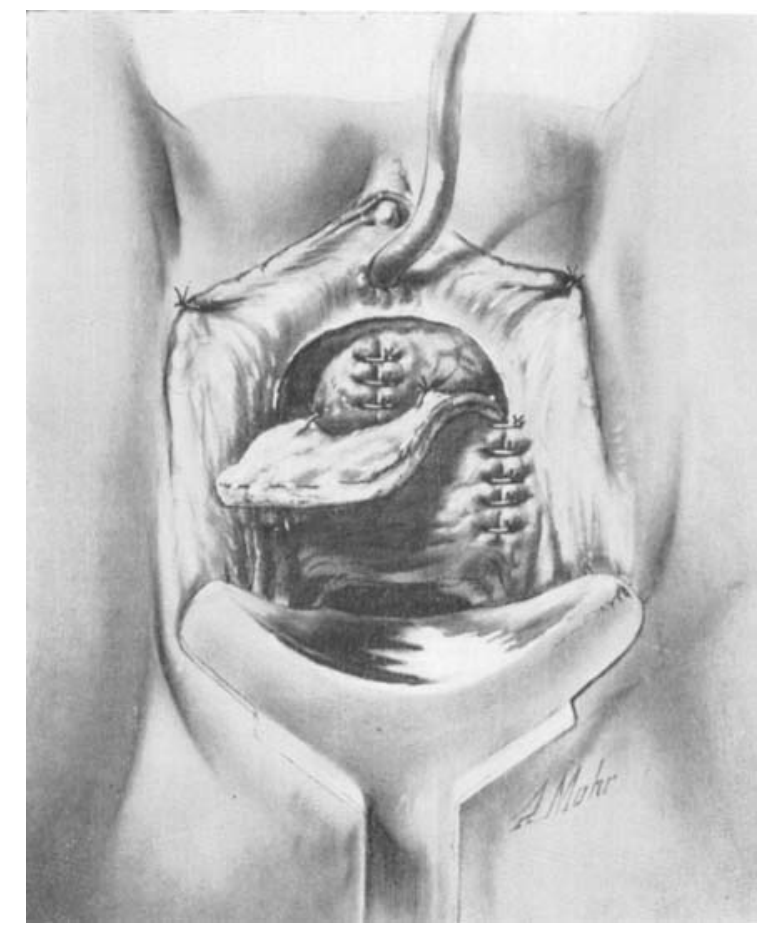

FIG. 5

The repaired urethra is covered by replacing the anterior vaginal wall.

but a decreased length as well. In this situation it is necessary to use a combined approach. First, the defect in the urethral floor is approached transvaginally, excised, and the urethral edges approximated. Before the vaginal flap is replaced a suprapubic approach is made, and lengthening and fixation of the roof of the urethra is performed. The suprapubic wound is closed and the final step is to suture the vaginal flap into place.

\section{REFERENCES}

LAPIDES, J. (1958). J. Urol., 80, 341.

- (1959). Med. Clin. N. Amer., 43, 1629.

Lapides, J., Ajemian, E. P., Stewart, B. H., Breakey, B. A., and Lichtwardt, J. R. (1960 a). J. Urol., 81, 86.

- $(1960$ b). Surg. Gynec. Obstet., 111, 224.

Lapides, J., Hodgson, N. B., Boyd, R. E., Shook, E. L., and Lichtwardt, J. R. (1958). J. Urol., $79,707$.

LAPIDES, J., SweEt, R. B., and Lewis, L. W. (1957). J. Urol., 77, 247.

Nesbit, R. M., and LAPIDES, J. (1948). J. Urol., 59, 726.

TANG, P., and Ruch, T. C. (1955). Amer. J. Physiol., 181, 249.

WOODBURNe, R. T. (1960). J. Urol., 81, 79. 